\title{
İlk ve Acil Yardım Laboratuvarında Uygulanan Simülasyon Eğitiminin Öğrencilerin Temel Beceri Düzeyine Etkisi*
}

\author{
The Effects of Basic Skills Level of Emergency and First Aid Laboratory of Applied \\ Simulation Training Students*
}

Özge AKBABA (iD, Bahadır TERCAN (iD, Sinan TARSUSLU (D), Serap UZUNER YURT iD

ÖZ

Araştırma, paramedik öğrencilerine simülasyon laboratuvarında verilen eğitimin beceri düzeyine etkisini belirlemek amaciyla yapıldı. Araştırmanın evrenini Ekim 2017-Mayıs 2018 eğitimögretim yılı güz/bahar döneminde Erzincan Binali Yıldırım Üniversitesi Sağlık Hizmetleri Yüksekokulu Paramedik bölümünde öğrenim gören 60 öğrenci oluşturdu. Entübasyon ile kalp masaj1 uygulaması teorik olarak anlatılıp, laboratuvarda öğretim elemanı gözetimiyle üç simülasyon denemesi yapıldıktan sonra veri toplama araçları uygulandı. Uygulamadan önce öğrencilerin beceri düzeyleri "yaptı" "yapmadı" şeklinde değerlendirilerek ön test, üçüncü günün sonunda yapmış olduğu uygulamalar son test olarak kabul edildi. Öğrencilerin uygulama öncesi ve sonrası işlem basamaklarını doğru yapma oranlarının karşılaştırılmasında McNemar analizi kullanıldı. Çalışmaya katılan öğrencilerin 45'i (\%75) bayan, 37'sinin (\%61,7) anadolu lisesinden mezun olduğu, 55'inin $(\% 91,7)$ herhangi bir mesleki deneyime sahip olmadığ1, yaş ortalamasının 19,08 $\pm 1,04$ yıl olduğu ve akademik not ortalamasının $2,41 \pm 0,82$ olduğu saptand1. Öğrencilerin simülasyon öncesi ve sonrası "kalp masajı" ve "entübasyon" işlem basamaklarının bazılarında istatistiksel olarak anlamlılık tespit edildi $(\mathrm{p}<0.001)$. Araştırmamıza katılan öğrencilerin simülasyon eğitimi sonrasında kalp masajı ve entübasyon uygulamalarını doğru yapma oranlarının arttığı belirlendi. Simülasyon laboratuvarında uygulanan eğitimin öğrencilerin uygulama becerilerinin düzeylerini artırdığı düşünülmektedir.

Anahtar Kelimeler: Beceri, Entübasyon, Kalp masaj1, Paramedik, Simülasyon

\begin{abstract}
The aim of this study was to determine the effect of education on paramedic students on the level of knowledge and skills. The population of the study consisted of 60 students studying in Paramedic Department of Erzincan Binali Yildirim University Vocational School in the fall/spring semester of October 2017May 2018 academic year. The application of "cardiac massage" and "intubation" was explained theoretically and three simulation experiments were conducted with the supervision of the instructor in the laboratory and data collection tools were applied. Before applying, students skill levels (did-didn't) was done by evaluating the pre-test form. At the end of the third day, the applications were accepted as the final test. McNemar analysis was used to compare the rate of students performing pre - and post-treatment steps correctly. In the study, 45 (75\%) the women students participated, $37(61,7 \%)$ of them graduated from Anatolian high school, 55 $(91,7 \%)$ of them did not have any professional experience, and the average age was $19,08 \pm 1,04$ years and the academic mean was $2,41 \pm 0,82$. Statistically significant significance was found in some of the pre - and post-simulation cardiac massage and intubation steps $(\mathrm{p}<0.001)$. It was determined that the rate of making heart massage and intubation applications right after simulation training increased. It is thought that the training applied in the simulation laboratory increases the students' application skills.
\end{abstract}

Keywords: Skill, Intubation, Cardiac massage, Paramedic, Simulation

\section{GíRiş}

Hastane öncesi acil sağlık hizmetlerinde daha kaliteli ve güvenilir bir hizmet sağlamak için paramediklerin hastaları iyi bir şekilde değerlendirebilecek tıbbi bilgi, beceri ve tutuma sahip olması gerekmektedir. Bunun için mesleki eğitim sürecinde teorik alt yapılarının ve uygulamalı eğitimlerinin özverili, disiplinli ve ciddi bir şekilde sağlanması gerekmektedir (1).
Sinan TARSUSLU (更), Bahadır TERCAN, Sinan TARSUSLU, Serap UZUNER YURT

Erzincan Binali Ylldırım Üniversitesi SHMYO

e-mail: sinan.tarsuslu@erzincan.edu.tr

*Bu Çalışma Erzincan Binali Yıldırım Üniversitesi Bilimsel Araştırma Projeleri Koordinasyon Birimi Tarafindan Desteklenmiştir. Proje No: TSA2017-497 
Günümüz eğitim ve öğretim sürecinde farklı teknolojiler kullanılmaktadır. Sağlık eğitiminde bilgi ve becerilerin geliştirilmesi için kullanılan bilgisayar destekli eğitimler ve simülasyon öğretim sürecinde büyük önem taşımaktadır. Öğrencilerin, hasta bakım yönetiminde yeterliliğinin geliştirilerek yetkinlik kazanması için simülasyon kullanımı önemli yer tutmaktadır (2). Simülasyonun ilk kullanım alanına baktığımızda askeri manevralar ve havacılıkta kritik beceri tekniklerini geliştirmeye yönelik olduğu bilinmektedir. Son yıllarda ise sağlık alanında çok önemli bir eğitim arac1 olarak görülmektedir. Simülasyon gerçekte var olan davranışların, ilişkilerin, araç gereçlerin, görevlerin ya da bazı bilişsel aktivitelerin taklit edilmesi olarak tanımlanmaktadır. Benzetim olarak da adlandırılan bu yöntemin gün geçtikçe kullanımı daha da artmaktadır. Teknoloji ve simülasyon entegrasyonuyla birlikte verilen sağlık hizmetleri hızla gelişim kaydetmektedir (3-5).

Klinik becerilerin gerçek hastalar üzerinde uygulamadan önce beceri laboratuvarlarında maketler, standardize veya simüle hastalar üzerinde öğrenilmesi, hümanistik sağlık eğitiminin temel bileşenlerindendir (6,7). Öğrencilerin klinik uygulamaları ilk önce hasta üzerinde gerçekleştirmesi, onlara kendini yeterli hissedememe, yanlış yapma ve hastaya zarar verme endişesi oluşturarak strese sokmaktadır. Simülasyon kullanımı ve beraberinde yapılan tekrarlı uygulamalar; öğrencilerin öğrenme sürecine aktif olarak katılımını sağlayarak onlara deneyim kazandırmakta (hastanın durumunu anlama, karar verme, değerlendirme, problem çözme, teknik beceri, ekip çalışması, yönetim ve iletişim becerisi), gerçek hayatta yapılabilecek hatalı uygulamaları azaltarak hasta güvenliğini arttırmakta ve öğrenmeye destek veren ortamıyla öğrencilerin anksiyetelerini azaltarak özgüvenlerini arttırmaktadır (2,8-13). Bu sonuçlarla birlikte simülasyon hasta haklarına uygun ve hastanın risk almadığ 1 bir tıbbi bakım hizmeti sunulmasını sağlamaktadır (14).

Günümüzde hasta güvenliğinin dışında etik ve yasal yaptırımların varlığ 1 , sağlı eğitiminde öğrencilerin kazanmaları gereken becerileri sinırlandırmaktadır. Eğitimde çözüm olarak görülen simülasyonun kullanımı son yıllarda çok yaygınlaşmıştır. Öğrenci sayısındaki artış, eğiticilerin sayısındaki sınırlılık ve en önemlisi hasta güvenliğini sağlamak amaciyla paramedik eğitiminde simülasyonun kullanımı önem kazanmıştır. $\mathrm{Bu}$ açıdan paramedik eğitiminde, ilerleyen teknolojinin sağladığ 1 olanakların kullanılması ve değerlendirilmesi önemlidir.

\section{MATERYAL VE METOT}

\section{Araştırma Tipi}

Araştırma, paramedik öğrencilerine simülasyon laboratuvarında verilen eğitimin beceri düzeyine etkisini belirlemek amacıyla yarı-deneysel tipte yapıldı.

\section{Evren ve Örneklem}

Araştırmanın evrenini Ekim 2017-Mayıs 2018 eğitimöğretim yılı güz/bahar döneminde Erzincan Binali Yıldırım Üniversitesi SHMYO Paramedik bölümünde öğrenim gören, Resusitasyon dersini alan 60 öğrenci oluşturdu. Araştırmada örneklem seçimine gidilmeyerek ilgili dersi alan ve çalışmaya katılmayı kabul eden tüm öğrenciler araştırmaya dâhil edildi.

\section{Veri Toplama Araçları}

Verilerin toplanmasında, simülasyon maketleri, öğrencilerin tanımlayıcı özelliklerini içeren soru formu ve entübasyonkalp masajı beceri değerlendirme formları kullanıldı.

Simülasyon Maketleri: Gerçeklik düzeyi düşük olan parça görev öğreticileri olarak adlandırılan simülatörlerden kalp masajı ve entübasyon uygulama maketleri kullanılmıştır (15).

Tanımlayıcı Özellikleri İçeren Soru Formu: Öğrencilerin cinsiyeti, yaşı, mezun olduğu lise durumu, mesleki deneyimin olup olmama durumu, akademik başarı durumu ile ilgili sorulardan oluşmaktadır.

Beceri Değerlendirme Formları: $\mathrm{Bu}$ formlardaki uygulama basamakları 2015 ERC (European Resuscitation Council) Kılavuz dikkate alınarak araştırmacılar tarafından geliştirilmiştir (16). Öğrencilerin simülasyon maketleri üzerinde yapmış olduğu uygulamaları yaptı veya yapamadı şeklinde belirleyerek değerlendirilmesini sağlamaktadır.

\section{Verilerin Toplanması}

Entübasyon ve kalp masajı uygulama yöntemleri ayrı ayrı teorik olarak öğrencilere anlatıldı. Daha sonra laboratuvarda bu iki uygulama tüm öğrencilere maket üzerinde bir defa gösterildi. Ardından her öğrenci laboratuvara tek tek alınarak, herhangi bir süre sınırı konulmadan öncelikle kalp masaj1 ve daha sonra entübasyon uygulamasının yapılmas1 istendi. Öğrenci seçimi ise 2017-2018 güz döneminde kaydı bulunan 60 öğrenci uygulamaya rastgele alınarak yapıldı. Mevcut laboratuvar olanaklarıyla üç öğretim elemanı gözetiminde öğrencinin simülasyon maketleri 
üzerinde uygulama basamakları yaptı-yapmadı şeklinde değerlendirilerek ön test olarak kaydedildi. Kalp masajı ve entübasyon uygulaması daha sonra öğrenciler tarafindan ikinci kez tekrarlandı ve bu aşamada uygulama formu kullanılmadı. Bu uygulamalar üçüncü defa öğrenciler tarafından yapilırken formlar değerlendirilerek son test olarak kabul edildi.

Öğrencilere teorik eğitim verildikten sonra yapılan birinci uygulama ön test olarak kabul edildi. Beceriyi geliştirmek amacıyla ikinci defa uygulamalar tekrar edildi. $\mathrm{Bu}$ aşama sonrası öğrencilerin eksik olduğu basamaklar maket üzerinde gösterilerek pekiştirilmesi amaçlandı. Daha sonra üçüncü uygulama yapılarak son test olarak kabul edildi. Öğrencilerin uygulama basamakları aynı sıra ve standartta formlar kullanılarak değerlendirildi. Teorik eğitim verildikten sonra ilk gün ön test, ikinci gün ara uygulama ve üçüncü gün ise son test yapılarak toplamda üç günde çalışma tamamlandı.

Uygulamadan önce öğrencilerin beceri düzeyleri “yaptı”, "yapmadı" şeklinde değerlendirilerek ön test olarak kabul edildi. Her uygulama sonrasında öğrencilerin yapmakta zorlandığı uygulamalar tekrar tekrar anlatıldı. Üçüncü günün sonunda yapmış olduğu uygulamalar son test olarak kabul edildi. Öğrencilerin ilk uygulama öncesi ve üçüncü gün uygulama sonrasında aldıkları puanlar karşılaştııılarak simülasyona dayalı eğimin, temel beceri düzeylerine etkisi belirlendi.

\section{Verilerin Değerlendirilmesi}

Verilerin değerlendirilmesi bilgisayar ortamında SPSS (Statistical Package for the Social Sciences) 16.0 istatistik programı kullanılarak yapıldı. Önemlilik düzeyi $\mathrm{p}<0.05$ olarak alındı. Değerlendirilmede; öğrencilerin tanımlayıcı özellikleri frekans analiziyle tespit edildi. Öğrencilerin uygulama öncesi ve sonrası işlem basamaklarını doğru yapma oranlarının karşılaştııılmasında McNemar analizi kullanıldi.

\section{Etik Kurul Onayı ve İzinler}

Çalışmaya başlamadan önce 28.09.2017 tarihli Erzincan Binali Yıldırım Üniversitesi İnsan Araştırmaları Etik Kurulu'ndan yazılı izin alındı. Çalışmaya katılan öğrenciler araştırmanın amacı ve veri toplama araçları hakkında bilgilendirildi. Gönüllü olan öğrencilerden sözlü ve yazılı onam alındı. Araştırmanın yürütülebilmesi için SHMYO Müdürlüğü'nden yazılı izin alındı.

\section{BULGULAR}

Çalışmaya katılan öğrencilerin $45^{\prime} \mathrm{i}(\% 75)$ bayan, $15^{\prime} \mathrm{i}$ (\%25) erkek ve yaş ortalamasının 19,08 $\pm 1,04$ yıl olduğu tespit edildi. Akademik not ortalamaları dörtlük sisteme göre $(4,00) 2,41 \pm 0,82$ olarak gözlemlendi. Mezun olunan lise durumu incelendiğinde 23 'ünün $(\% 38,3)$ sağllk meslek lisesi, 37'sinin $(\% 61,7)$ anadolu lisesinden mezun olduğu ve mesleki deneyim durumlarına bakıldığında 5 'inin $(\% 8,3)$ ön lisans programına başlamadan deneyim sahibi olduğu, 55'inin $(\% 91,7)$ herhangi bir mesleki deneyime sahip olmadığı tespit edildi (Tablo1).

Tablo 1. Katılımcılara ait tanımlayıcı istatistikler

\begin{tabular}{llll}
\hline Demografik veriler & $\mathrm{n}$ & $\%$ & $\overline{\boldsymbol{X}}$ \\
Cinsiyet: & $\mathbf{6 0}$ & $\mathbf{1 0 0}$ & \\
Erkek & 15 & 25 & \\
Bayan & 45 & 75 & $19,08 \pm 1,04$ \\
\hline Yaş ortalaması: & $\mathbf{6 0}$ & $\mathbf{1 0 0}$ & $2,41 \pm 0,82$ \\
\hline Akademik not ortalaması: & $\mathbf{6 0}$ & $\mathbf{1 0 0}$ & \\
\hline Mezun olunan lise: & $\mathbf{6 0}$ & $\mathbf{1 0 0}$ & \\
Sağlık Meslek Lisesi & 23 & 38,3 & \\
Anadolu Lisesi & 37 & 61,7 & \\
\hline Mesleki deneyim: & $\mathbf{6 0}$ & $\mathbf{1 0 0}$ & \\
Evet & 5 & 8,3 & \\
Hayır & 55 & 91,7 & \\
\hline
\end{tabular}


Araştırma kapsamına alınan öğrencilerin eğitim öncesi ve sonrası entübasyon işlem basamaklarını doğru yapma oranlarının karşılaştırılması Tablo 2'de verildi. Öğrencilerin "Hastanın başına pozisyon verme" (eğitim öncesi \%30, eğitim sonrası \%95), "Laringoskop kullanarak glottisi görme" (eğitim öncesi \%23, eğitim sonras1 \%95), "Laringoskopu sol elle tutma" (eğitim öncesi \%68,3, eğitim sonrası \%91,7), "Bleydi, dişler arasından ağzın sağ tarafina yerleştirme" (eğitim öncesi \%68,3, eğitim sonras1 \%96,7), "Dili sola alarak üstünden uvula görülene kadar yavaşça içeriye doğru ilerletme" (eğitim öncesi \%60, eğitim sonras1 \%91,7), "Ucu orta çizgide tutulan bleydi, epiglot ve dil kökü arasına yerleştirme" (eğitim öncesi \%43, eğitim sonras1 \%90), "Dişleri koruyarak laringoskopu ağız tavanına doğru (yukarı ve öne) kaldırma" (eğitim öncesi \%23,3, eğitim sonras1 \%93,3), "Larenks ağzını ve beyaz vokal kordları görme" (eğitim öncesi \%40, eğitim sonrası \%91,7), “Tüpü, ağzın sağ tarafından, kaf hemen vokal kortların altında kalacak ve çizgisi görülecek şekilde yerleştirme" (eğitim öncesi \%41,7, eğitim sonrası \%93,3), "Dişlere zarar vermeden laringoskopu çıkarma" (eğitim öncesi \%60, eğitim sonrası \%95), "Stile tüpü içinden çıkarma" (eğitim öncesi \%66,7, eğitim sonras1 \%95,0), "Tüpün kafinı yeterli miktarda şişirme" (eğitim öncesi $\% 63,3$, eğitim sonras1 \%93,3), "Tüpü, solunum devresine bağlama" (eğitim öncesi \%45, eğitim sonras1 \%93,3), "Yüksek konsantrasyonda oksijen vermeye başlama" (eğitim öncesi $\% 41,7$, eğitim sonrası \%93,3), "Steteskopla dinleme noktalarını oskülte ederek, her iki akciğerin eşit havalandığını belirleme" (eğitim öncesi $\% 30$, eğitim sonrası \%93,3), "Epigastrumu dinleme" (eğitim öncesi \%26,7, eğitim sonrası \%83,3), "Hazırlanan flaster veya bandaj ile tüpü hastaya sabitleme" (eğitim öncesi $\% 33,3$, eğitim sonras1 \%91,7) işlem basamaklarını doğru yapma oranları eğitim öncesine göre arttığı ve aralarındaki farkın istatistiksel olarak anlamlı olduğu belirlendi $(\mathrm{p}<0.05)$ (Tablo 2).

Öğrencilerin simülasyona dayalı eğitim öncesi ve sonrası kalp masajı işlem basamaklarını doğru yapma oranlarının karşılaştırılması Tablo 3'de belirtilmiştir. Buna göre; "Yukarıdan aşağıya dik bir şekilde, dirsekler bükülmeden sternuma $5 \mathrm{~cm}$ basınç oluşturacak şekilde kompresyon uygulanması" (eğitim öncesi \%60 eğitim sonras1 \%93,3), "Eller sternum alt yarısı üzerinden kaldırılmadan dekompresyon fazına geçilmesi ve kompresyon, dekompresyon sürelerinin eşit olmasının sağlanması" (eğitim öncesi \%35, eğitim sonrası \%71,7) işlem basamaklarını doğru yapma oranları eğitim öncesine göre arttığı ve aralarındaki farkın istatistiksel olarak anlamlı olduğu belirlendi $(\mathrm{p}<0.05)$ (Tablo 3).
Tablo 2. Öğrencilerin simülasyona dayalı eğitim öncesi ve sonrası entübasyon işlem basamaklarını doğru yapma oranlarının karşılaştırılması

\begin{tabular}{|c|c|c|c|c|c|}
\hline \multirow[t]{2}{*}{ İşlem Basamakları } & \multicolumn{2}{|c|}{$\begin{array}{l}\text { Eğitim } \\
\text { Öncesi }\end{array}$} & \multicolumn{2}{|c|}{$\begin{array}{l}\text { Eğitim } \\
\text { Sonrası }\end{array}$} & \multirow[t]{2}{*}{ p değeri } \\
\hline & Sayı & $\%$ & Sayı & $\%$ & \\
\hline $\begin{array}{l}\text { Entübasyon } \\
\text { malzemelerini } \\
\text { hazırlayınız. }\end{array}$ & 52 & 86,7 & 57 & 95,0 & $\mathrm{p}=0.227$ \\
\hline $\begin{array}{l}\text { Hastanın başına pozisyon } \\
\text { veriniz. }\end{array}$ & 18 & 30,0 & 57 & 95,0 & $p<0.05$ \\
\hline $\begin{array}{l}\text { Larengoskop kullanarak } \\
\text { glottisi görünüz. }\end{array}$ & 14 & 23,3 & 57 & 95,0 & $p<0.05$ \\
\hline $\begin{array}{l}\text { Laringoskopu sol elle } \\
\text { tutunuz. }\end{array}$ & 41 & 68,3 & 55 & 91,7 & $p<0.05$ \\
\hline $\begin{array}{l}\text { Bleydi, dişler arasından } \\
\text { ağzın sağ tarafına } \\
\text { yerleștiriniz. }\end{array}$ & 41 & 68,3 & 58 & 96,7 & $p<0.05$ \\
\hline $\begin{array}{l}\text { Dili sola alarak üstünden } \\
\text { uvula görülene kadar } \\
\text { yavaşça içeriye doğru } \\
\text { ilerletiniz. }\end{array}$ & 36 & 60,0 & 55 & 91,7 & $p<0.05$ \\
\hline $\begin{array}{l}\text { Ucu orta çizgide tutulan } \\
\text { bleydi, epiglot ve dil kökü } \\
\text { arasına yerleştiriniz. }\end{array}$ & 26 & 43,3 & 54 & 90,0 & $p<0.05$ \\
\hline $\begin{array}{l}\text { Dişleri koruyarak } \\
\text { laringoskopu ağız } \\
\text { tavanına doğru (yukarı ve } \\
\text { öne) kaldırını. }\end{array}$ & 14 & 23,3 & 56 & 93,3 & $p<0.05$ \\
\hline $\begin{array}{l}\text { Larenks ağzını ve beyaz } \\
\text { vokal kordları görünüz. }\end{array}$ & 24 & 40,0 & 55 & 91,7 & $p<0.05$ \\
\hline $\begin{array}{l}\text { Tüpü, ağzın sağ } \\
\text { tarafından, kaf hemen } \\
\text { vokal kortların altında } \\
\text { kalacak ve çizgisi } \\
\text { görülecek şekilde } \\
\text { yerleştiriniz. }\end{array}$ & 25 & 41,7 & 56 & 93,3 & $p<0.05$ \\
\hline $\begin{array}{l}\text { Dişlere zarar vermeden } \\
\text { laringoskopu çıkarınız. }\end{array}$ & 36 & 60,0 & 57 & 95,0 & $p<0.05$ \\
\hline Stile tüp içinden çıkarınız. & 40 & 66,7 & 57 & 95,0 & $p<0.05$ \\
\hline $\begin{array}{l}\text { Tüpün kafını yeterli } \\
\text { miktarda şişiriniz. }\end{array}$ & 32 & 53,3 & 56 & 93,3 & $p<0.05$ \\
\hline $\begin{array}{l}\text { Tüpü, solunum devresine } \\
\text { bağlayınız. }\end{array}$ & 27 & 45,0 & 56 & 93,3 & $p<0.05$ \\
\hline $\begin{array}{l}\text { Yüksek konsantrasyonda } \\
\text { oksijen vermeye } \\
\text { başlayınız. }\end{array}$ & 25 & 41,7 & 56 & 93,3 & $p<0.05$ \\
\hline $\begin{array}{l}\text { Steteskopla dinleme } \\
\text { noktalarını oskülte } \\
\text { ederek, her iki akciğgerin } \\
\text { eşit havalandığını } \\
\text { belirleyiniz. }\end{array}$ & 18 & 30,0 & 56 & 93,3 & $p<0.05$ \\
\hline Epigastrumu dinleyiniz. & 16 & 26,7 & 50 & 83,3 & $p<0.05$ \\
\hline $\begin{array}{l}\text { Hazırlanan flaster veya } \\
\text { bandaj ile tüpü hastaya } \\
\text { sabitleyiniz. }\end{array}$ & 20 & 33,3 & 55 & 91,7 & $\mathrm{p}<0.05$ \\
\hline
\end{tabular}

(Önemlilik düzeyi $\mathrm{p}<0.05$ olarak alındı. ) 
Tablo 3. Öğrencilerin simülasyona dayalı eğitim öncesi ve sonrası kalp masajı işlem basamaklarını doğru yapma oranlarının karşılaştırılması

\begin{tabular}{|c|c|c|c|c|c|}
\hline \multirow{2}{*}{ İşlem Basamakları } & \multicolumn{2}{|c|}{ Eğitim Öncesi } & \multicolumn{2}{|c|}{ Eğitim Sonrası } & \multirow{2}{*}{ p değeri } \\
\hline & Sayı & $\%$ & Sayı & $\%$ & \\
\hline $\begin{array}{l}\text { Malzemelerin } \\
\text { hazırlanması. }\end{array}$ & 54 & 90,0 & 59 & 98,3 & $\mathrm{p}=0.125$ \\
\hline $\begin{array}{l}\text { Hastanın omuzları } \\
\text { hizasında diz } \\
\text { çökülmesi }\end{array}$ & 55 & 91,7 & 60 & 100 & $\begin{array}{c}\text { Test } \\
\text { yapılmadı }\end{array}$ \\
\hline $\begin{array}{l}\text { Hastanın ayak ucuna } \\
\text { doğru olan elin işaret } \\
\text { ve orta parmaklarıyla } \\
\text { bulunduğunuz taraftaki } \\
\text { arkus kostarium alt } \\
\text { ucundan başlayarak } \\
\text { palpe edilmesi }\end{array}$ & 49 & 81,7 & 60 & 100 & $\begin{array}{c}\text { Test } \\
\text { yap1lmad } 1\end{array}$ \\
\hline $\begin{array}{l}\text { Her iki arkus } \\
\text { kostariumun } \\
\text { birleştiği noktada } \\
\text { ksifoid çıkıntısının } \\
\text { hissedilmesi }\end{array}$ & 51 & 85,0 & 60 & 100 & $\begin{array}{c}\text { Test } \\
\text { yapılmadı }\end{array}$ \\
\hline $\begin{array}{l}\text { Orta parmağın ksifoid } \\
\text { çıkıntının üzerine, } \\
\text { işaret parmağı } \\
\text { sternumla ksifoid } \\
\text { çıkıntının birleştiği } \\
\text { yere konulması }\end{array}$ & 50 & 83,3 & 60 & 100 & $\begin{array}{c}\text { Test } \\
\text { yap1lmad1 }\end{array}$ \\
\hline $\begin{array}{l}\text { Diğer elin topuk kısmı, } \\
\text { hastanın orta hattında } \\
\text { olacak şekilde, bu } \\
\text { iki parmağın yanına } \\
\text { yaklaştırılması }\end{array}$ & 44 & 73,3 & 60 & 100 & $\begin{array}{c}\text { Test } \\
\text { yap1lmad } 1\end{array}$ \\
\hline $\begin{array}{l}\text { Ksifoid çıkıntıyı } \\
\text { bulmak için kullanılan } \\
\text { elin, sternum alt } \\
\text { yarısına yerleştirilen } \\
\text { elin üzerine konulması }\end{array}$ & 57 & 95,0 & 52 & 86,7 & $\mathrm{p}=0.227$ \\
\hline $\begin{array}{l}\text { Yukarıdan aşağıya } \\
\text { dik bir şekilde, } \\
\text { dirsekler bükülmeden } \\
\text { sternuma } 5 \mathrm{~cm} \\
\text { basınç oluşturacak } \\
\text { şekilde kopresyon } \\
\text { uygulanması }\end{array}$ & 36 & 60,0 & 56 & 93,3 & $\mathrm{p}<0.05$ \\
\hline $\begin{array}{l}\text { Eller sternum alt } \\
\text { yarısı üzerinden } \\
\text { kaldırılmadan } \\
\text { dekompresyon } \\
\text { fazına geçilmesi } \\
\text { ve kompresyon, } \\
\text { dekompresyon } \\
\text { sürelerinin eşit } \\
\text { olmasının sağlanması }\end{array}$ & 21 & 35,0 & 43 & 71,7 & $\mathrm{p}<0.05$ \\
\hline $\begin{array}{l}30 \text { kalp masajı } \\
\text { olacak şekilde işlem } \\
\text { gercekleștirilmesi }\end{array}$ & 51 & 85,0 & 58 & 96,7 & $\mathrm{p}=0.065$ \\
\hline
\end{tabular}

Önemlilik düzeyi $\mathrm{p}<0.05$ olarak alındı.

\section{TARTIŞMA}

2013 yılında Dünya Sağlık Örgütü (WHO) sağlık bölümlerinde okuyan öğrencilerin eğitimine yeni bir yaklaşım getirilmesi gerektiğini vurgulayan bir rapor yayımladı. Bu raporda, sağlık bölümlerinde okuyan öğrencilerin öğrenimlerini geliştirmek ve pekiştirmek için simülasyonun önemi vurgulanmıştır (17). Simülasyon gerçekte gerçekleşecek olan bir olayı taklit eder (18). Ayrıca, simülasyon gerçekte gerçekleşecek olayların güvenli bir ortamda tekrar tekrar yapılmasını ve öğrencilerin bunu yaparken uygulama becerilerini geliştirmeyi ve başarısızlıklarını öğrenmelerini sağlar. Bu nedenle, hastaları riske atmadan simülasyona dayalı eğitimle öğrencilerin uygulama becerilerini geliştirmek mümkündür (19). Son yıllarda yapılan araştırmalar, simülasyon temelli eğitim ile olumlu öğrenme sonuçlarının ilişkili olduğunu göstermektedir (20).

Araştırmamıza katılan öğrencilerin kalp masajı ve entübasyon uygulamalarına yönelik işlem basamaklarının çoğunda doğru yapma oranlarının simülasyona dayalı eğitimle artmış olduğu gözlenmiştir (Tablo 2-3). Bu sonuçla, simülasyona dayalı eğitimin öğrencilerin uygulama becerilerini arttıran bir öğrenme yöntemi olduğu söylenilebilir. Aşağıda araştırmamız doğrultusunda literatürde yer alan çalışmalar sırasıyla tartışılmıştır.

Öztürk ve arkadaşları yaptığı çalışmada, simülasyona dayalı eğitim sonrası paramedik bölüm öğrencilerinin Kardiyopulmoner Resisütasyon uygulamalarına yönelik işlem basamaklarını doğru yapma durumlarının istatistiksel olarak anlamlı şekilde arttığ Abelsson ve arkadaşları yaptığı çalışmada, hastane öncesi acil bakım hizmetlerinde simülasyonun, hemşirelerin travma bakımıyla ilgili bilgilerini artırdığını ve uygulama becerilerini geliştirdiğini saptamışlardır (22). Kim simülasyon eğitimi öncesi ve sonrası hemşirelik öğrencileri üzerinde kardiyak arrest yönetimi için gerekli olan becerileri değerlendirdiği çalışmasında, eğitim sonrası özgüven $(p<0.001)$, öz yeterlilik $(p<0.001)$ ve eleştirel düşünme becerilerinin $(\mathrm{p}<0.001)$ istatistiksel olarak anlamlı şekilde arttığını bildirmiştir (23). Sapiano ve arkadaşları yaptığı çalışmada, sanal simülasyonun farklı programlardaki hemşirelik öğrencileri için etkili öğrenme aracı olduğunu ve internetin var olduğu her yerde kolay erișimle bilgilerin tekrarlanarak bilgi düzeyini önemli derecede artırdığını saptamışlardır (24). Aggar ve arkadaşları yaptığı çalışmada, simülasyon kullanılarak bir zaman yönetimi müdahalesi yapılarak hemşirelik öğrencilerinin, klinik ortamda 
ilaç uygulamasına daha hazırlıklı oldukları $(\mathrm{p}<0.034)$ sonucunu ortaya koymuştur (25). Mete ve arkadaşları yaptığı çalışmada, simülasyon uygulanması yapıldıktan sonra öğrencilerin kişisel kontrollerinin $(\mathrm{p}=0.014)$ ve sorun çözme becerilerinin $(\mathrm{p}=0.038)$ istatiksel olarak anlamlı şekilde arttı̆̆ belirtilmiştir (26). Özkal ve Çayır yaptığı çalışmada, simülasyon uygulamalarının hemşirelik mesleği için faydalı olduğu $(\% 89,9)$ sonucuna varmıştır (27). Ünver ve arkadaşları yaptığı çalışmada, tatbikatlarda simülasyon faaliyetlerinin kullanılmasıly hemşirelik öğrencilerinin afetlere karşı hazırlık algılarının $(\% 42,5)$ olumlu yönde etkilendiği sonucuna ulaşmıştır (28). Eyikara ve Baykara yaptığı çalışmada, simülasyonun hemşirelik bölümü öğrencilerinin yaşamsal bulguları ölçebilmeleri konusunda olumlu bir etkiye sahip olduğunu, $(p<0.05)$ yani öğrencilerin bu konuda gerekli olan bilgi ve psikomotor becerilerini geliştirmede simülasyonun önemli etkisinin olduğunu saptamıştır (29). Crowe ve arkadaşları yaptığı çalışmada, simülasyonun genel tıp merkezlerinde çalışan hemşirelerin güvensizlik durumlarını keşfetme ve eleştirel bir şekilde düşünmelerine olanak tanıyan bir ortam sağlayarak, durumları kötüleşen hastalara yanıt vermede hemşirelerin bilgi ve güven düzeylerini istatistiksel olarak anlamlı bir şekilde artırdığı sonucuna varmışlardır $(\mathrm{p}<0.001)$ (30). Jarvill ve arkadaşları yaptığı çalışmada, hemşirelik öğrencilerinde ilaç yönetimi yetkinliğinin sağlanması konusunda simülasyonun öğrencilerin ilaç yönetimi yetkinliğini $(\mathrm{p}<0.00)$ geliştiğini saptamışlardır (31). Arslan ve arkadaşları simülasyon temelli hemşirelik eğitimi konusuyla ilgili yaptığı çalışmada, simülasyon eğitimi, pediatri hemşireliği öğrencilerinin uygulama becerileri konusunda öz-yeterlilik algısını artırırken $(\mathrm{p}<0.05)$ kayg1 düzeylerini azalttığı $(\mathrm{p}<0.05)$ sonucuna ulaşmıştır (32). Topbaş ve arkadaşları yaptığı çalışmada, Kardiyopulmoner sağlık problemlerinin belirlenmesi noktasında hemşirelik öğrencilerinin bilgi, yetkinlik ve memnuniyet düzeylerini yükseltmede simülasyona dayalı eğitimin etkili olduğu sonucu elde etmişlerdir $(p<0.001)$ (33). Kim-Godwin ve arkadaşları yaptığı çalışmada, toplum sağlığı uygulamasının bir parçası olan ev ziyaretleri konusunda yapılan simülasyona dayalı eğitim sonrasında öğrencilerin memnuniyet ve özgüven düzeylerinin artığını belirtmiştir $(\mathrm{p}<0.05)(34)$.

\section{SONUÇ VE ÖNERİLER}

Sonuç olarak araştırmamıza katılan öğrencilerin simülasyona dayalı eğitim sonrasında kalp masajı ve entübasyon uygulamalarını doğru yapma oranlarının arttı̆̆1 belirlenmiştir. Simülasyon laboratuvarında uygulanan eğitimin öğrencilerin uygulama becerileri düzeylerini $\operatorname{artırdığı~düşünülmektedir.~Acil~durum~ve~olağanüstü~}$ durumlarda hasta/yaralıya ilk müdahalede bulunacak olan paramedik bölüm öğrencilerinin mesleki becerisi büyük bir öneme sahiptir. Bu açıdan yapmış olduğumuz araştırma ile simülasyona dayalı eğitimin öğrencilerin beceri düzeylerini geliştirmede önemli olduğu belirlenmiştir. $\mathrm{Bu}$ yüzden, sağlık personeli yetiştiren üniversiteler ve liselerde öğrencilerin uygulama becerilerini istenilen düzeyde geliştirmek için simülatör maketlerinin kullanılması önerilmektedir. Laboratuvarların sürekli olarak yenilenmesi ve son teknolojiye uygun olarak tasarlanması, laboratuvar çalışmalarının düzenlenmesi, öğrencilerin birebir çalışması ve bu uygulamalarda simülatörlere daha çok yer verilmesi önerilir. Çalışmada karşılaş̧ı̆̆ımız zorluklar; kullanılan simülatör maketleri son teknolojik simülatörlere göre düşük bir model olması ve laboratuvar ortamının beceri değerlendirme uygulamaları için uygun şartları sağlayamaması (öğrencilerin uygulama esnasında öğretim elemanlarını görmesi, uygulama sonrası öğrencilerin laboratuvar dışında iletişime geçmesi vb.) olarak ifade edilebilir.

\section{KAYNAKLAR}

1. Tentillier E, Heydenreich C, Cros AM, Schmitt V, Dindart JM, Thicoipe M. "Use of the intubating laryngeal mask airway in emergency pre-hospital difficult intubation." Resuscitation, 2008; 77: 30-4.

2. Durham CF, Alden KR. Chapter 51: Enhancing patient safety in nursing education through patient simulation. In: Hughes RG, editör. Patient Safety and Quality: An Evidence-Based Handbook for Nurses. Agency for Healthcare Research and Quality, Rockville. [Erişim Tarihi: 22 Aralık 2018]. http:// www.ahrq. gov/qual/nurseshdbk/.

3. Nehring WM, Lashley FR. "Nursing simulation: a review of the past 40 years." Simulation \& Gaming, 2009; 40(4): 52852.

4. Bradley P. "The history of simulation in medical education and possible future directions." Medical Education, 2006; 40: 254-62.

5. Jeffries P.R. "Clinical Simülations in Nursing Education. Advenced Concepts, Trends and Opportuties." Wolters Kluwer Health: Lippincott Williams \& Wilkins. 2014.

6. Ziv A. "Simulators and Simulation - Based Medical Education." In: Dent J, Harden RM, eds. A Practical Guide for Medical Teacher. (211-220). London: Elsevier Limited. 2005.

7. Ziv A, Wolpe PR, Small SD, Glick S. "Simulaton Based Medical Education: An Ethical Imperative.” (783-788). Acad Med. 2003. 
8. Dikici M.F, Yarış F. "Ondokuz Mayıs Üniversitesi Tıp Fakültesi Klinik Beceri Eğitiminde Standardize ve Simüle Hasta Programı.” Türkiye Klinikleri J Med Sci, 2007; 27: 738-43.

9. Rodgers DL. High-fidelity Patient Simulation: A Descriptive White Paper Report. Healthcare Simulation Strategies. Retrieved; from http:// sim-strategies.com/downloads/ Simulation \%20White\%20Paper2.pdf. [Erişim Tarihi: 12.02.2018].

10. Weller JM. "Simulation in undergradute medical education: Bridging the gap between theory and practice." Med Educ. 2004; 38: 22-38.

11. Patrik J. "Simulation. In: Patric J, ed. Training: Research and Practice.” (487-508). London: Academic Press. 2002.

12. Karaöz S. "Hemşirelikte klinik öğretime genel bir bakış ve etkin klinik öğretim için öneriler.” Hemşirelikte Araştırma ve Geliştirme Dergisi, 2003; 5(1): 15-21.

13. Medley CF, Horne C. "Using simulation technology for undergraduate nursing education." Journal of Nursing Education, 2005; 44(1): 31-4.

14. Çiçek AÇ, Ardıç C, Bilir Ö. "Evde Sağlık Hizmetleri Eğitiminde Simülasyona Dayalı Tıp Eğitiminin Rolü: Recep Tayyip Erdoğan Üniversitesi Tıp Fakültesi Örneği.” Klinik Tıp Aile Hekimliği Dergisi,2018; 10(5).

15. Sezer H, Orgun F. "Hemşirelik Eğitiminde Simülasyon Kullanımı ve Simülasyon Modeli." Ege Üniversitei Hemşirelik Fakültesi Dergisi, 2017; 33(2): 140-52.

16. Monsieurs K.G, Nolan J.P, Bossaert L.L, Greif R, Maconochie I.K, Nikolaou N.I. et all. "European resuscitation council guidelines for resuscitation 2015 section 1. Executive summary." Resuscitation, 2015; 95: 1-80.

17. World Health Organization, Transforming and Scaling Up Health Professionals' Education and Training: World Health Organization Guidelines. WHO, Geneca, Switzerland. 2013a.

18. O'Connor, T. "The role of simulation in nursing education." Nurs.N.Z, 2014; 20(1): 11-3.

19. Bashaw M. "Integrating simulations into perioperative education for undergraduate nursing students." AORN J, 2016; 103(2): 211-15.

20. Weller J.M, Nestel D, Marshall S.D, Brooks P.M, Conn J.J. "Simulation in clinical teaching and learning." Med. J. Aust, 2012; 196(9): 594.

21. Öztürk D, Gürol A, Uslu S, Yücel O. "İlk ve Acil Yardım Programında Okuyan Öğrencilere Ambulans Simülasyon Laboratuvarında Uygulanan Eğitimin Temel Beceri Düzeyine Etkisi.” HSP, 2017; 4(1): 25-31.

22. Abelsson A, Rystedt I, Suserud B.O, Lindwall L. "Learning High-Energy Trauma Care Trough Simulation." Clinical Simulation in Nursing, 2018; 17: 1-6.
23. Kim E. "Effect of simulation-based emergency cardiac arrest education on nursing students' self-efficacy and critical thinking skills: Roleplay versus lecture." Nurse Education Today, 2018; 61: 258-63.

24. Sapiano A.B, Sammur R, Trapani J. "The effectiveness of virtual simulation in improving student nurses' knowledge and performance during patient deterioration: A pre and post test design." Nurse Education Today, 2017; 62: 128-33.

25. Aggar C, Bloomfield J.G, Frotjold A, Thomas T.H.T, Koo F. "A time management intervention using simulation to improve nursing students' preparedness for medication administration in the clinical setting: A quasi-experimental study." Collegian, 2018; 25: 105-11.

26. Mete M, Gümüş F, Zengin L, Erkan M, Sürücü H.A, Yiğitalp G. ve ark. "Mesleki Beceri Laboratuvarında Uygulanan Simülasyon Yönteminin Öğrencilerin Sorun Çözme Becerileri Üzerindeki Etkisinin İncelenmesi.” JAREN, 2017; 3(2): 92-6.

27. Özkal F, Çayır A. "Opinions of Nursing Students towards Simulation Efficiency in Nursin Education. International Journal of Humanities and Social Science Invention." 2016; 5(12): 32-6.

28. Ünver V, Başak T, Taştan S, Kök G, Güvenc G, Demirtaş A. ve ark. "Analysis of the effects of high-fidelity simulation on nursing students' perceptions of their preparedness for disasters." International Emergency Nursing, 2018; 38: 3-9.

29. Eyikara E, Baykara ZG. "Effect of simulation on the ability of first year nursing students to learn vital signs." Nurse Education Today, 2018; 60: 101-6.

30. Crowe S, Ewart L, Derman S. "The impact of simulation based education on nursing confidence, knowledge and patient outcomes on general medicine units." Nurse Education in Practice. 2018; 29: 70-5.

31. Jarvill M, Jenkins S, Akman O, Astroth KS, Pohl C, Jacobs PJ. "Effect of Simulation on Nursing Students' Medication Administration Competence." Clinical Simulation in Nursing, 2018; 14: 3-7.

32. Arslan FT, Türkmen AS, Çelen R, Özkan S, Altıparmak D. Şahin A. "Comparing Traditional and Simulation-Based Experiences in Pediatrics with Undergraduate Nursing Students in Turkey." Clinical Simulation in Nursing, 2018; 16: 62-9.

33. Topbaş E, Bingöl G, Görgen Ö, Terzi B, Yılmaz A. "The Effects of Simulation Training on Identifying Cardiopulmonary Health Problems." International Journal of Health Sciences \& Research, 2017; 7(8): 253-61.

34. Kim-Godwin YS, Livsey KR, Ezzell D, Highsmith C, Winslow H. Aikman AN. "Students Like Peer Evaluation during Home Visit Simulation Experiences." Clinical Simulation in Nursing, 2013; 9: 535-42. 